\title{
Human health in nature - towards a holistic philosophy of nutrition
}

\author{
Klaus Michael Meyer-Abich* $\ddagger$ \\ Department of Philosophy of Nature, University of Essen, Germany
}

\begin{abstract}
Objective: To explain how the philosophy of nutrition is part of the philosophy of health. To show that this link allows practical solutions for equity and sustainability. Method: An analysis of the historical philosophies concerned with nutrition and health. A comparison of the definitions in the history of mind from antiquity to the beginning of the twenty-first century.

Conclusion: We are not individually healthy, but we are so in togetherness, even with animals and plants. Comprehensive nutrition science has physical, social and environmental attributes. It follows that nutrition is good for the enhancement of good company with human beings as well as with the connatural world. We recognise that we owe to others what we are and this constitutes the equity of being.
\end{abstract}

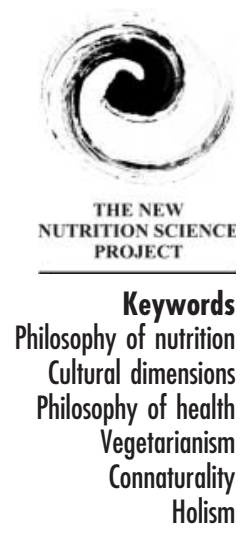

Nutrition has been linked with health by all civilisations. Any discussion about the philosophy of nutrition must be part of the philosophy of health. Nutrition and health are central dimensions of the way of life, which has been known since antiquity as diata. The present-day constriction of this broad meaning to the term 'diet' covers only the aspects of eating and drinking and is a symptom of the reductionism of our age.

A timely and more meaningful nutrition science has to embrace not only the physical and biological aspects of eating and drinking, but also social and environmental concerns of which animals and plants are an important part. There is wide agreement now that nutrition is part of our social fabric and that the contacts during meals are a strong bonding force, but the same is true for human relations to the connatural world. This is recognised by Goethe's saying that 'we owe others what we are', which constitutes the equity of being. The consequences of Goethe's philosophy connotes for nutrition, that we have to give animals and plants a chance to develop and live their own life, before they serve as our food.

This implies that sustainable methods to obtain food, like organic farming, should replace conventional food production and exploitation of resources. It also implies that animals and plants are not mere resources and that our eating and drinking should enhance the world, as Goethe might have put it. This philosophical view of nutrition

‡Correspondence address: Charitas-Bischoff-Treppe 9, D-22587 Hamburg, Germany. could transform our anthropocentric view to a position where nature itself is the centre of our reference.

\section{Discussion}

Claudius Galenus, usually known as Galen (129-199), the Greco-Roman physician and philosopher of medicine, considered nutrition to be one of the six non-naturalia affecting human health by means of their influence on the balance between the corporeal humours. These six aspects are 'not natural' in the sense that they are cultural; that is, part of the overall ways of life, or of diaita in the Greek sense, which was much broader than what nowadays has remained to be called 'diet'. The other five aspects of healthy life identified by Galen were the environment, rest (including sleep) and motion, or exercise, evacuations (including sexuality), and the state of the mind, or inner harmony ${ }^{1}$.

Two of the aspects refer to our firm rooting in the outer world (nutrition and the environment) while two correspond to these from within (digestion and the state of the mind); the last two concern the permeability between inside and outside (sleep, or other forms of rest, and motion). This is a modern interpretation of Galen's non-naturalia, but it refers to the Hippocratic and Platonic tradition which was also Galen's background. For instance, dreams were recognised as a mediating element of health between the part and the whole in ancient medicine, and Plato emphasised in his dialogue Timaios the symmetry of mental and physical motion $^{2}$. 
Goethe said in his play about the poet Tasso: You owe to others what you are. For nutrition this means that nature is to be rewarded for keeping us alive. Good nutrition and good health are not determined at the individual level. A meal tastes better and may also be more nourishing when enjoyed in good company with human and non-human beings. Or does this fish still taste as good, when we remind ourselves that it was taken from an impoverished country, or caught by over-fishing? Nutrition should be a science of co-being in nature.

Nutrition as now defined appears to be an element of health in relation of the individual to its environment. Moreover there is no doubt that patterns of nutrition are cultural achievements. As the Hippocratic author of the book on Ancient Medicine put it: 'If we knew like the horses or the cattle what food suited us best, medicine would never have come into being' ${ }^{3}$. We might add that the same is true for nutritional science. Lacking the natural wisdom of animals, we expect medicine as well as nutritional science to explain health to us and to recommend how to lead a healthy life.

Horses and cattle apparently are not concerned with doubts or questions. They simply go ahead and eat what they like. Humans often enough do so as well, but they make far more mistakes in eating what they believe to be good for them. To some extent nutrition science can be helpful here, but this ends where basic cultural orientations and convictions are challenged, when people refuse not only to accept the scientific answers but even renounce the questions which are asked. Exactly this is the domain of philosophy that is most easily defined as dealing with those questions which neither ordinary nor scientific consciousness is prepared to ask. With respect to nutrition, such philosophical issues include questions such as:

- Equity within humankind (for instance, direct or indirect transfers from the poor to the rich).

- Equity between humankind and our connatural world, which is to say, the living and natural worlds including animals, plants, land- and seascapes.

- Sustainability in the long run.

\section{Health, or disease care?}

Since we are strongly health-oriented one might expect to find a philosophy of health almost as easy as information on the subject of health itself. But this awareness does not seem to exist neither in ordinary nor in scientific thinking. We rather find that Western physicians know very much (if not all) about diseases, but very little about health. Even prevention for them means only to identify emerging diseases as early as possible and not to lead a healthy life. They simply do not take any note of you as long as you are not sick. This was completely different in antiquity. Galen, for instance, wrote a comprehensive six-volume book on health: two on sustaining health, or living healthy; three about the effects of nutrition - foods of plant as well as animal origin - on health; and one on the corresponding physiology of the human body ${ }^{1}$.

Galen considered himself a student of Hippocrates (460-377 BC) or the Hippocratic school, which is the origin of modern medicine. For the philosophy of nutrition it is particularly promising that in this tradition health philosophically is conceived not only as an individual but also as a social and common property in nature. The limits of individuality are a well-known issue in nutritional science, since nutrition obviously is a cultural phenomenon not to be dealt with only at the level of the individual.

\section{Health of the parts and of the whole}

The Hippocratic philosophy of health was developed to its highest level by Plato (427-347 BC), Hippocrates' younger contemporary. In the third book of his political philosophy of nature (Politeia, or 'The State') ${ }^{4}$, the necessity to get beyond the individual level is demonstrated by referring to a man by the name of Herodikos who was sufficiently wealthy that he did not have to work but was very frail in health. Being familiar with the medical knowledge of his time, however, he succeeded in fighting every sickness that befell him so that he grew very old - but this was all he achieved in life. His only contribution to sustain the world was to sustain his individual health for a long life, but for nothing else apart from that.

In Plato's philosophical context this biography looked strange but implied a very important lesson, namely that bealth is not a goal in itself. Of course, all people should care for their health, but as a precondition for something else. This ultimate goal in Plato's sense is a 'good' life, or to bring about what one is competent to achieve among others. In modern terms, self-actualisation - the top of Maslow's pyramid of needs ${ }^{5}-$ is a corresponding idea. In both cases individual health is only an intermediate, though most important objective: the faculty to lead one's own life, as a scientist, artist, architect, carpenter, sailor, physician, etc.

In modern terms the main point in Plato's Hippocratic philosophy of health is that health - as well as disease - is not an individual property but refers to our coexistence 
with others. There is no single human being but everybody is what he or she is only in togetherness with other beings, human as well as non-human. With respect to health and disease this again is the basic message of modern epidemiology, particularly as a follow-up of Marmot's Whitehall studies ${ }^{6,7}$. We are not individually healthy but we are so in relating ourselves to others, and the same is true for diseases. Health is a sociopsychosomatic phenomenon $^{8}$, and so is nutrition when taken as a matter of health.

Indeed, the social or socio-political character of health has been pointed out appropriately by recommendation 'Health 21' of the World Health Organization (WHO) 9 . This says that health is not only the business of health ministries or agencies, but that practically every political activity - in economics, work, traffic, education, etc. - affects the health of the population. However, WHO does not go as far as to include our community with the connatural world ${ }^{10,11}$.

For nutrition, good company tends to be appreciated when eating meals but is usually not considered as part of the meal. This looks different when health is recognised as a social phenomenon, or as an attribute of togetherness, and nutrition is considered as a matter of health. A meal not only tastes better, but may also be more nourishing, when taken in good company and atmosphere. According to the holistic interpretation of health as well as nutrition, such environmental factors are not accessories but are indeed part of the meal. Nutrition science should be developed as a science of co-being, or of connaturality as well. In other words, the visible meal is entangled with an invisible meal; neither is adequately nourishing without the other.

The visible meal may be vegetables and fish or meat. The invisible meal may be cruelty to animals in factory farming or fairness in organic farming; destroyed or conserved wetlands in agriculture; selfish interests or corporate social responsibility in food business; and so on. If a meal is taken at the expense of others, there is also the hidden company of these. We may become more aware of the visible as well as the invisible meal on our plates, and the holistic experience can enhance as well as spoil the appetite. Nutrition science so far has mainly been concerned with the visible meal; it should also become aware of the invisible part.

A traditional test for the quality of a meal is whether God - or nature - may be praised for the provision of a particular meal. Religion here can to some extent be replaced by moral consciousness. Thus, does this excellently prepared fish still taste good when we remind ourselves that it was taken from a poor country which was not adequately compensated for it? Moreover, the fish may have been caught by over-fishing. Such moral reflections lead us into the issues of equity.

\section{Equity reconsidered for evolution}

Equity usually refers to the distribution of entitlements and all types of wealth. Many individuals may share a common wealth in common relations, but so far the international world order is that of the strong dealing with the weak. Solutions are not easily found at this level.

Yet equity also refers to being as well as to having ${ }^{12}$, and this goes beyond any political issue. As Goethe put it in his theatre play on Tasso, the poet: You owe to others what you $a r e^{13}$. This is easily understood if one considers parents, teachers, friends and partners. We became what we are in togetherness with them, by being loved, educated, supported, criticised and accepted, in common ways of life. To be due to them what one is, means to return or give what has been given - particularly love, support and acceptance. In other words: to be oneself and do one's own not only for oneself but for them as well.

This, moreover, is not restricted to our personal environment since parents, friends and the other people in our lives again owe to others what they are, so that ultimately the 'others' to whom we owe ourselves are all the others or at least the particular culture within which one grew up. This includes the ancestors who built up that culture, from Hippocrates and Plato to Goethe and beyond. To all of them and finally to humankind itself we owe what we are as social individuals.

The equity of being is most easily appreciated within humankind. But if we look around in nature we observe that to owe one's being to others seems to be a universal principle. Plants, for instance, live from the four elements of life (which are different from the chemical elements): soil, water, air and light are what they need to grow from a seed. They owe their existence, therefore, to those elements that come together to become a plant. At the same time they are due what they are to generate offspring and to feed animals including man. These in turn owe their being to the plants that provided food for them as well as to their parents and to the social formation that let them grow up.

Often enough such dependencies are symmetrical. Fruits, for instance, serve as food for birds, while these serve the plants to distribute their seeds; or the flowers of plants feed insects while these pollinate the plants. The general situation, however, is not that animals or plants owe themselves mutually what they are but that all these debts and dependencies are balanced within a more or less embracing whole, or finally in nature herself. Everything in nature owes itself to others in the double sense of being fed by others as well as feeding others.

Some people feel desperate about this general eating and being eaten. But being eaten in nature generally means a metamorphosis to a different level of reality, an enhancement in Goethe's sense. It would give rise to despair if as a rule there were mere consumption or destruction instead of enhancement, but this is not the case. The energy of light is harvested by leaves and finds its way into wine. Insects and worms eaten by a bird are not just destroyed but converted into a bird's flight. This is indeed a kind of transubstantiation. Isn't the bird, as 
Heraclitus put it, in his way 'living up the death' of the worm?

How does humankind fit into this picture? Like all other animals we live at the expense of other's lives and we couldn't live at all if we did not do so. Beyond nutrition we also appropriate the rest of the world as 'resources' for what we need or believe to need. All this being taken from nature, there is no doubt that we owe ourselves to nature. But what is it in particular that we owe for that? What do we give for being given? All the other beings owe their existence to nature and they pay their debt by serving for some enhancement, generally speaking: by possibly leaving the world a little better or evolved further than when they came in. This being the basic pattern of evolution, do we human beings also leave the world a little better than when we came in?

This question is not easily answered. Certainly it cannot be answered generally for all cultures and epochs. But there is good reason to believe that the human species now is giving more to consumption, or destruction, than to enhancement. Also we have replaced cultivation (like in agri-culture) by mere production, and conservation by exploitation.

This could perhaps be justified if among millions of species only humankind were allowed to serve itself without serving others. If this were so we might indeed be allowed to treat the world as a bag of resources and not have to care for its enhancement, conservation and cultivation. But we cannot justify any such claim ${ }^{10,11}$.

\section{Nutrition as a model for sustainable development}

To bite a living being or parts of it in pieces between one's teeth is a precondition of human life that most people prefer not to acknowledge. Of those who do, many become vegetarians. This solution, however, is disputed in Christianity as well as in Buddhism because plants are living beings too ${ }^{14}$. The philosophy of nutrition presented here offers a different solution.

What is proposed here is that health, as well as nutrition, are attributes of togetherness, or connaturality within the whole. Parts are relating themselves to one another, but their overall pattern of relations must fit into the whole. When taking nutrition as an attribute of connaturality, questions of equity cannot be answered for individuals relating themselves to other individuals without referring to the rest of the world. Within the animal kingdom it cannot be decided whether one individual is justified to eat another. A decision can only be drawn within and with respect to the benefit of the whole. The vegetarian answer, however, is based on incomplete reasoning, if taking into account that plants are fellow creatures as well.

It is not possible to avoid living at the expense of other's lives. Heraclitus was right in stating that we live upon other beings' death, their death being 'enhanced' into our life. We cannot get around that. But if we owe our being to other beings, plants and animals, what do we owe for human nutrition? Our debt for living at the expense of others must be acknowledged at three levels ${ }^{11}$.

\section{Animal and plant breeding}

Animals as well as plants should have a chance to live their proper life before they are slaughtered or harvested. With respect to animals, this means that feedlots or factory farming in general is not morally acceptable. If there are people who want to eat meat and cannot afford to buy it from naturally raised animals in organic farming, this is a social issue which does not justify cruelty to animals. Meat from animals who have lived before being slaughtered is about twice as expensive as meat from feedlots, but this can easily be compensated by eating only half as much. This will be healthier anyway, since the statistical average of $200 \mathrm{~g}$ meat per person per day in Germany is high for a sedentary society.

Cruelty usually is not observed with respect to plants. But they are sensitive beings and how do we know whether industrial plant production allows for proper living before they are harvested? Whether industrial plant production is any better than animal feedlots is an open question. The idea to 'produce' living beings does not even allow for these questions. Production, therefore, should be replaced by cultivation, and exploitation should be replaced by conservation.

\section{Cooking and eating}

Since we must accept that we do not only live at the expense of other being's lives but also live up or enhance their death in the strict sense, we owe them gratitude for allowing us to go on living. This might sound cynical if the particular beings just eaten were addressed, but they again owe their lives to nature and ultimately nature is feeding all of us, so that nature as a whole is the one to be grateful to. Once more there is no balance below relating ourselves to the whole. Practically, this implies to be sure of good cooking since what we eat deserves to be appreciated.

\section{Enhancement or consumption}

We should consider our use or abuse of the strength that is given to us by the plants or animals we eat. Do we use that strength for enhancement or for destruction (mere consumption) in nature? What is meant to be enhancement may turn out to be destruction as we are making mistakes; but often enough this is not really a problem. For instance, it cannot be justified to use the strength received from a fish for activities that pollute the ocean so that finally no more fish could live there. The world would certainly look much better if we had considered for every meal that we ate what we owe for it, to do or to omit.

It is the same fundamental rule to be observed on these three levels, namely to consider: What do we owe for that? In agriculture or 'animal culture', in cooking or eating and finally in changing the world by means of the power 
received from the living beings which we have eaten what do we owe to nature for living upon other beings' death? 'We' here are not only individual people but social institutions as well. Food companies, for instance, usually look after their reputation, and to serve health is their basic corporate social responsibility. According to the foregoing philosophy of nutrition this responsibility is considerably broader than many people in industry have been aware of so far.

When unexpected guests once visited Heraclitus they found him in the kitchen and felt embarrassed to meet this distinguished man in such an undistinguished situation. Heraclitus, however, is reported to have invited them saying: 'Come in, there are gods even here'! If nutrition is indeed a matter of human health in nature, Heraclitus' invitation could refer to nutritional science as well. Even scientists who consider themselves as atheists should have no problem here because in Greek religion gods were the creative powers in nature, and Heraclitus was the first one to indicate nature's unity or wholeness.

This view of the gods also suggests an orientation on how the basic criterion may be applied: What do we owe to nature for living upon other being's death? While the moral wisdom of beginning a meal with a prayer rests in the fact that one cannot thank God for something undeservedly appropriated, this wisdom may easily be secularised now. Indeed, to find out what we owe for a particular food, it helps to consider whether we can be grateful to nature for providing it to feed us. Nutrition is wholesome as far as the whole can be praised for its provision. Or in other words: Do and take only what nature grants and may be praised for. This rule goes beyond nutrition, but its truth is most immediately felt here so that considering nutrition may indeed help us to become better human beings.

\section{Conclusion}

Nutrition is a matter of health ${ }^{1,2}$, so that the philosophy of nutrition becomes part of the philosophy of health. While the Hippocratic diaita (way of life) has shrunk to 'diet' in modern times, a comprehensive nutrition science should be concerned with diaita in the broad sense again ${ }^{11}$.

From Plato to modern epidemiology and social medicine, health has been considered a socio-psychosomatic phenomenon. We are not individually healthy but we are so in togetherness, even with animals and plants. The same is true for nutrition, since company or loneliness is part of the meal. The facts to be taken into account by a comprehensive nutrition science, therefore, are physical as well as social and environmental.

Health - and nutrition, accordingly - is not an end in itself as shown by Plato ${ }^{4}$. It follows that nutrition is good for the maintenance and enhancement of good company with human beings as well as with the connatural world.
In good company we recognise that we owe others what we are $^{13}$ : from parents and partners to plants and animals. This constitutes the equity of being.

To owe others what we are implies in nutrition first to re-emphasise culture in agriculture, replacing exploitation by conservation and 'production' by cultivation, so that plants and animals have a chance to live before they are harvested or killed to feed us. Second, to be grateful to nature for feeding us and to act accordingly signifies that plants and animals are not mere 'resources'. Third, to consider what we owe nature for staying alive by nutrition replacing mere consumption by enhancement, so that a world with humankind might turn out better than without.

These rules address individuals and institutions alike, for instance food companies that care for their reputation. A comprehensive nutrition science will consider where our food comes from; will not appropriate resources but accept gratefully what is granted, and will no longer remain anthropocentric but study the contribution of nutrition to human health in nature of which we are a part.

\section{References}

1 Galenus C. De sanitate tuenda. In: Kühn CG, ed. Claudii Galeni Opera Omnia, vol. 6. Hildesheim: Olms, 1965.

2 Plato. Timaeos. In: Eigler G, ed. Werke in acht Bänden (writings in 8 volumes Greek/German), vol. 7. Darmstadt: Wissenschaftliche Buchgesellschaft, 1972.

3 Hippocrates. Ancient Medicine. In: Jones WH, ed. Hippocrates, vol. 1. Cambridge, MA/London: Harvard University Press/Heinemann, 1923.

4 Plato. Politeia [The Republic]. In: Eigler G, ed. Werke in acht Bänden (writings in 8 volumes Greek/German), vol. 4. Darmstadt: Wissenschaftliche Buchgesellschaft, 1971.

5 Maslow AH. Motivation and Personality. New York: Harper \& Row, 1954.

6 Marmot MG. Social inequalities in mortality: the social disease mortality. In: Wilkinson RG, ed. Class and Health: Research and Longitudinal Data. London: Tavistock, 1986; $21-33$.

7 Rose G. The Strategy of Preventive Medicine. Oxford: University Press, 1992.

8 Evans RG, Barer ML, Marmor TR, eds. Why are Some People Healthy and Others Not? The Determinants of Health of Populations. New York: Aldine de Gruyter, 1994.

9 World Health Organization (WHO). Life in the 21st Century - A Vision for All. Geneva: WHO, 1998.

10 Meyer-Abich KM. Revolution for Nature - From the Environment to the Connatural World. Cambridge, UK: The White Horse Press, 1993; Denton, TX: University of North Texas Press, 1994.

11 Meyer-Abich KM. Praktische Naturphilosophie - Erinnerung an einen vergessenen Traum [Practical Philosophy of Nature - Recollection of a Forgotten Dream ]. München: $\mathrm{CH}$ Beck, 1997.

12 Fromm E. To Have or to Be? New York: Harper \& Row, 1976.

13 Goethe JW. Torquato Tasso. In: Trunz E, ed. Goethes Werke, vol. 5. München: Verlag CH Beck, 1981.

14 Schmithausen L. The case of vegetarianism - a Buddhist perspective. Journal of Indian Philosophy 2002; 12(1): 309-29. 